DOI: https://doi.org/10.33739/2587-5434-2020-3-70-77

\title{
TEACHING THE SCIENTIFIC STYLE OF THE RIVERS OF THE FUTURE ARCHITECTS AND BUILDERS IN KNUCA: ACHIEVEMENTS, PROBLEMS, PERSPECTIVES
}

\author{
Elena Mospan \\ PhD, Associate Professor \\ Natalia Bessonova \\ Senior lecturer \\ Olga Greul \\ Senior lecturer \\ Kharkiv National University \\ construction and architecture (KHNUCA) \\ (Kharkiv, Ukraine) \\ e-mail: elena.mospan@gmail.com \\ bessonova.natalya.ua@gmail.com \\ gruel.olga@,gmail.com
}

\begin{abstract}
Annotation. Article deals with searching for reserves for increasing the effectiveness of teaching foreign students to the scientific style of speech in the condition of reducing the study time. A comparative analysis of the classic manuals of the $80 \mathrm{~s}$ of the twentieth century and educational materials created at the Kharkiv National University of Construction and Architecture was carried out. The continuity of these textbooks is noted. An assessment of the level of compliance of their thematic content with the most important disciplines that are taught to future architects and builders during their first and second years of basic training is given. The directions for improving the existing training materials were defined and the emphasis on the need for a preliminary linguistic and methodological justification of the proposed changes was done.
\end{abstract}

Keywords: construction and architecture, teaching foreign students, scientific style of speech, thematic content of textbook, educational materials

\section{ОБУЧЕНИЕ НАУЧНОМУ СТИЛЮ РЕЧИ БУДУЩИХ АРХИТЕКТОРОВ И СТРОИТЕЛЕЙ В ХНУСА: ДОСТИЖЕНИЯ, ПРОБЛЕМЫ, ПЕРСПЕКТИВЫ}

\author{
Елена Мосьпан \\ Кандидат филологических наук, доцент \\ Наталия Бессонова \\ Старший преподаватель \\ Ольга Греул \\ Старший преподаватель \\ Харьковский национальный университет \\ строительства и архитектуры (ХНУСА) \\ (Харьков, Украина) \\ e-mail: elena.mospan@gmail.com \\ bessonova.natalya.ua@gmail.com \\ gruel.olga@gmail.com
}

\begin{abstract}
Аннотация. Целью данного исследования стал поиск резервов для повышения эффективности обучения иностранных студентов научному стилю речи в условия сокращения учебного времени. Был проведен сравнительный анализ классических пособий 80-х годов XX века и созданных в Харьковском национальном университете строительства и архитектуры учебных материалов.
\end{abstract}


Отмечена преемственность этих учебных пособий. Дана оценка уровня соответствия их тематического наполнения наиболее важным дисциплинам, которые преподаются будущим архитекторам и строителям на первом и втором году профильной подготовки. Были определены направления совершенствования имеющихся учебных материалов и сделан акцент на необходимости предварительного лингвистического и методического обоснования предлагаемых изменений.

Ключевые слова: строительство и архитектура, обучение иностранных студентов, научный стиль речи, тематическое наполнение, учебные материалы.

\section{ВВЕДЕНИЕ}

Украинские вузы имеют более чем полувековой опыт подготовки специалистов для зарубежья. Распределение иностранных учащихся по городам Украины (по данным сайта https://studyinukraine.gov.ua) свидетельствует о том, что главным центром, предоставляющим такие услуги, является Харьков. Так, например, в 2019 году из 80470 иностранных учащихся, получавших образование в Украине, более 20000 выбрали харьковские высшие учебные заведения. По статистике, архитектура и строительство находятся на втором месте по популярности среди иностранных студентов.

Карантинные мероприятия, введенные в Украине в середине марта 2020 года, существенно повлияли на подготовку иностранных специалистов. Сложившаяся ситуация располагает к обдумыванию методов интенсификации учебной деятельности иностранных студентов и поиску новых путей повышения качества их языковой подготовки, к эффективному использованию времени, высвободившегося в ожидании прибытия новых иностранных учащихся. Появилась возможность в этот юбилейный для нашего университета год (в октябре 2020 года ХНУСА отмечает 90-летие) подвести итоги работы, очертить круг актуальных проблем, рассмотреть варианты их решений, определить «точки роста» эффективности нашей работы и наметить планы на будущее.

ЦЕЛЬЮ данной статьи является анализ (через призму сложившейся традиции обучения научному стилю речи) учебно-методических разработок, используемых в настоящее время для языковой подготовки будущих архитекторов и строителей в Харьковском национальном университете строительства и архитектуры - вузе, выпускники которого ценятся во всем мире, а диплом попрежнему считается одним из наиболее престижных среди высших учебных заведений Украины. Также предполагается выявить методический потенциал еще не охваченных вниманием наших методистов базовых дисциплин, которые читаются студентам специальностей «Архитектура и градостроительство» и «Строительство и гражданская инженерия».

\section{ОБЗОР ЛИТЕРАТУРЫ}

Обучение научному стилю речи (НСР) как отдельный аспект языковой подготовки иностранных студентов, методика которого начала складываться в 70-х годах прошлого столетия, в наше время является общепризнанной необходимой частью работы на подготовительных отделениях и на базовых факультетах. Его теоретические основы изложены в трудах Г.И. Володиной, Н.М. Лариохиной, Е.И. Мотиной, А.Д. Митрофановой, Л.П. Клобуковой и др. Самым известным практическим результатом исследований в данном направлении, а также основой для дальнейших разработок стала серия пособий по НСР (создававшихся как приложения к учебному комплексу «Старт») для студентов медико-биологического (Л.В. Колотилина, И.А. Борзова, Л.П. Донская и др.), технического (Т.Е. Аросева, Л.Г. Роговая Н.Ф. Сафьянова), экономического (А.В. Бирюкова, Л.П. Михайлик, Н.С. Федорова), филологического (И.В. Богатырева, Л.З. Голованова, И.Н. Лобашкова) профилей обучения, а также для будущих специалистов в области информатики и 
информационных технологий (И.Ф. Виноградова, О.А. Лаптева, Ю.А. Родинко и др.), увидевших свет в 80-х годах XX века.

Каждое пособие из данной серии содержит вводный курс, предназначенный для подготовки иностранных студентов к их первым занятиям по специальным предметам. Основная же часть этих учебных изданий посвящена изучению важнейших для научного дискурса логических тем, таких, как определение предмета, его качественная характеристика, классификация объектов, их состав и строение, характеристика процессов и т.п. В части пособий имеются материалы для обучения иностранных учащихся составлению плана текста и конспектированию с листа. Развивает данное методическое направление созданное в ХПИ пособие «Научная речь для начинающих» (Ясницкая 1994), в котором, в отличие от названных выше изданий, авторы принципиально использовали неадаптированные научные микротексты.

В соответствии с министерскими учебными планами, ввод предметов при своевременном заезде студентов, обеспечивающем 8 - 10 месяцев учебного времени, традиционно начинался с 6 - 8 недели обучения. И тогда из 720 аудиторных часов не менее 120 часов выделялось на НСР как отдельный аспект аудиторной работы. В таком случае студенты полностью выполняли программу, осваивая наиболее общие лексико-грамматические конструкции НСР, структурные особенности научных текстов и усваивая набор специально отобранных общенаучных и специальных терминов. Единственным объективным недостатком работы по подобным учебным пособиям является невозможность осуществления на их основе ранней узкоспециальной языковой подготовки.

Разработка пособий для профессионально ориентированного обучения языку уже традиционно проводится и преподавателями, работающими с иностранными учащимися на основном этапе языковой подготовки, главным образом, на первом и втором курсах, так как учебный процесс на третьем и четвертом курсах связан с обучением созданию вторичных научных текстов: аннотации, реферата и обзорного реферата.

Новый уровень учебных материалов для основного этапа обучения представляет учебный комплекс, созданный в ХНУРЭ творческим коллективом под руководством О.В. Петрушовой (Петрушова 2006, 2007). Он включает учебник грамматики для 1-2 курсов, сборник упражнений, в который заложена возможность отрабатывать темы из области синтаксиса простого и сложного предложений как на материале общелитературного, так и научного стиля речи, причем разных профилей обучения, а также по два пособия по НСР (отдельно для первого и второго курсов) для технических и экономических специальностей. Кроме синтаксиса простого предложения, на первом курсе предлагается обучать студентов конспектированию с листа, для чего в конце предложены специальные тексты, тематически связанные с базовым текстом урока. Данные тексты насыщены пройденными за год лексико-грамматическими конструкциями. Четкая авторская концепция, последовательно прослеживающаяся во всех частях комплекса, гарантирует выполнение учебной программы. Как и набор пособий по НСР 80-х годов XX века, это издание уже также становится образцом для создания новых специализированных учебников.

Сложившаяся методическая традиция и имеющиеся на сегодня учебные материалы, казалось бы, должны обеспечивать иностранцам достаточный для поступления на основные курсы уровень владения языком обучения, но в реальности этому препятствует временной фактор. Иностранные учащиеся прибывают на учебу все позже и позже, в связи с чем преподавателям зачастую приходится жертвовать именно обучением НСР во имя освоения минимально необходимого набора языковых явлений на основе общелитературного стиля. Результатом становится неготовность студентов к профессиональной коммуникации, как устной, так и письменной, и в рамках учебно-научного, и собственно научного подстилей. Еще одним негативным фактором стало существенно урезание учебных часов, выделяемых на языковую подготовку и на подготовительных, и основных факультетах. Как следствие, студенты подфаков выпускаются лишь с тем запасом базовых терминов, которые они усвоили в процессе изучения специальных предметов: математики, физики, химии, 
биологии, основ компьютерной графики и др. Как показывают опрос и результаты вступительного тестирования, некоторые учащиеся, приехавшие к началу второго семестра и позже, успевают пройти от $50 \%$ до $70 \%$ программного материала.

\section{МЕТОДЫ ИССЛЕДОВАНИЯ}

В таких условиях поиск путей повышения качества языковой подготовки и, прежде всего, обучения научному стилю речи, становится актуальнейшей проблемой. Отправным пунктом предлагается сделать анализ и сопоставление образовательных программ, разработанных для всех специальностей и находящихся, благодаря развитию Интернет-технологий, в большинстве случаев в свободном доступе. Особого внимания в образовательных программах в нашем случае заслуживают те дисциплины, на которые выделяется наибольшее количество учебных часов. Последующий сопоставительный анализ тематического наполнения используемых для языковой подготовки учебных пособий позволит сделать вывод необходимости или отсутствии необходимости их до - или переработки.

\section{РЕЗУЛЬТАТЫ}

Кафедрой украинского языка и языковой подготовки иностранных граждан ХНУБА на сегодня создан комплекс учебных материалов, обеспечивающий изучение грамматики, развитие навыков профессионального чтения и говорения, написания вторичных научных текстов на основе текстов и статей по специальности. Также имеются пособия, предоставляющие возможности для самостоятельной работы с текстами лингвострановедческой направленности, например, об архитектурно-исторических памятниках Харькова, Харьковской области и всей Украины. Учебные материалы комплектуются разработками для текущего и итогового контроля, преимущественно в тестовой форме, что позволяет при необходимости использовать их для контроля on-line.

Раннее начало узкоспециальной языковой подготовки обеспечивается работой по созданному на кафедре учебному пособию по НСР для подготовительных факультетов «Практикум "Учимся читать тексты по специальности”» (Бессонова 2017). Его первая часть посвящена таким общепринятым для этого этапа обучения темам, как положение предмета в пространстве, классификация и характеристика предметов по составу, строению, назначению и характеристики процессов изменения. Вторая же часть, собственно и вводящая будущих архитекторов и строителей в специальность, ориентирована на освоение таких тем, как величины, размеры, временна́я отнесенность сооружений, конструктивные элементы сооружений (фундамент, стены, перегородки, перекрытия, крыша и др.) и их функциональное назначение, описание строительных процессов (укладка, окраска, облицовка, отделочные работы и др.), характеристика основных строительных материалов (гранит, мрамор, цемент, бетон, железобетон, стекло, глина) и особенности их использования; имеются также краткие экскурсы в архитектуру Древних Египта, Греции и Рима, отдельных стран Азии (Китая, Индии, Японии) и Европы периода Средневековья.

Для профессионально ориентированной языковой подготовки на основных факультетах ХНУСА созданы пособия практикумы «Шаг в профессию»: для специальности «Архитектура и градостроительство» - авторским коллективом в составе Е.В. Беликовой, Н.Н.Бессоновой и О.А. Греул (Беликова 2020), для специальности «Строительство и гражданская инженерия» аналогичное пособие Л.В. Скрипник и Н.Г. Черногорской (Скрипник 2020). Первый практикум, кроме расширения словарного запаса и совершенствования навыков говорения и письма на такие профессиональные темы, как «Что такое архитектура?», «Профессия архитектора», «Конструктивные элементы зданий» и др., включает материалы для освоения предусмотренных программой для первого курса грамматических тем: выражение субъектно-предикатных, объектных и атрибутивных отношений в простом предложении. Аналогичные цели поставлены и во втором из двух названных выше практикумов, который тематически охватывает общие сведения о зданиях, сооружениях, 
рассказы о профессии строителя и строительной площадке, конструктивные элементы зданий, строительных материалах и изделиях из них, отдельных конструктивных частях помещений и др.

С целью активизировать использование пройденного лексико-грамматического материала в устной и письменной речи и подготовить иностранных учащихся основных факультетов к эффективному восприятию лекций было создано пособие «Читаем тексты самостоятельно» (Беликова 2019). В качестве вводных для него были отобраны тексты, посвященные конструктивным элементам зданий и свойствам строительных материалов, необходимые для продуктивного освоения следующих за ними тем «Семь чудес света», «Крестово-купольные постройки Византии», «Архитектура Древнего Киева», «Киево-Печерский заповедник», «Украинский модерн» и др.

Тематика учебных материалов в еще одном пособии «Читаем тексты по специальности» (авторы - Е.В. Беликова, Н.Н. Бессонова, О.А. Греул, Т.В. Креч (Беликова 2017) - не только архитектура, но и живопись. Умение компетентно (с использованием разнообразной специфической оценочной лексики) описывать живописные полотна обеспечивается проработкой специальных текстов, посвященных картинам «Весна» Боттичелли, «Джоконда» Леонардо да Винчи, портрету Павла III кисти Тициана. Работа над обзорными текстами о Ренессансе в Италии, классицизме в архитектуре Великобритании и Италии, раннем барокко в Италии и об украинском барокко позволяет иностранным студентам вступать в профессиональную коммуникацию высокого содержательного уровня, а также освоить составление аннотаций и небольшого реферата - умение, которое проверяется на государственном экзамене на знание языка обучения.

Как мы видим, имеющиеся учебные материалы для будущих архитекторов содержательно опираются на базовые темы из области истории архитектуры и изобразительного искусства или рассказывают о всемирно признанных живописных шедеврах и архитектурных памятниках.

Изучение образовательной программы специальности «Архитектура и градостроительство» наглядно показывает, что в цикле профессиональной и практической подготовки доминирует проектирование. На «Введение в архитектурно-градостроительное проектирование» выделено 405 учебных часов, на «Основы архитектурно-градостроительного проектирования» - еще 405 ч., а на само «Архитектурное и градостроительное проектирование» - рекордные 795 ч. Изучению «Истории искусства, архитектуры и градостроительства» отведено 540 ч. Кроме того, существенную часть учебного времени занимают «Изобразительное искусство» и «Конструкции зданий и сооружений»630 и 450 часов соответственно. На другие учебные курсы выделяется менее 200 и даже 100 часов. Такое распределение времени заставляет задуматься над изменением тематики учебных текстов или смещением содержательных акцентов в учебных пособиях по языковой подготовке, как минимум, в качестве эксперимента.

Курс «Архитектурное проектирование» включает изучение теоретических основ архитектуры и архитектурной композиции, принципов и методов проектирования общественных, промышленных и жилых зданий, требований к различным проектам, учет внешних факторов, а также овладение архитектурной графикой. Проведенный обзор имеющихся учебных пособий по НСР показывает, что ряд тем этого курса, являющихся базовыми для архитекторов, еще не охвачены учебными текстами. Например, основные понятия архитектурной графики, принципы, средства и приемы архитектурной композиции, составные части проекта, этапы проектирования, способы создания архитектурных проектов, требования к сооружениям и земельным участкам, планировка и интерьер помещений и некоторые другие. Речь не идет о подмене работы над этими темами преподавателя-предметника, но создание комплекта учебных материалов на их основе, на наш взгляд, существенно облегчит иностранным учащимся освоение их важнейшего предмета за счет снятия лексических и грамматических трудностей, а значит, станет следующим шагом к совершенствованию как языковой, так и предметной компетенции наших студентов.

Так как преподавание указанного курса, кроме анализа лучших архитектурных объектов прошлых веков и нашего времени, предполагает активное использование метода выполнения 
практических работ, включая выполнение композиционных упражнений, считаем необходимым предложить создавать соответственные учебные разработки. Кроме того, во взаимодействии или при поддержке преподавателей соответствующих профильных кафедр, можно и нужно стремиться к созданию учебных материалов по аудированию, например, с примерами описания конкретных выдающихся архитектурных объектов (их макеты имеются во многих учебных помещениях вуза). Отметим, что целенаправленное обучение слушанию в настоящее время - методическая «мертвая зона», что поясняется отсутствием или недоступностью лингафонных кабинетов и отсутствием у вузов необходимой технической базы. Для обучения продвинутому аудированию можно использовать записи реальных занятий, проведенных, например, on-line, посвященных разбору отдельных архитектурных сооружений. Для этого, естественно, потребуется взаимодействие с преподавателями профильных кафедр, от которого, на наш взгляд, выиграют все стороны учебного процесса. Опыт такого сотрудничества также является важнейшей наработкой конца прошлого века: тогда на подготовительных факультетах складывались и активно функционировали микроколлективы предметников, работающих в одной академической группе, во главе с куратором акадгруппы преподавателем, осуществляющим в ней языковую подготовку. Члены микроколлектива консультировали друг друга при создании учебных материалов, предметники координировали свою аудиторную деятельность с русистами, стараясь быть в курсе того, какую грамматику уже прошли студенты, а русисты по мере возможности заранее вводили и отрабатывали наиболее частотную лексику последующих занятий по специальным предметам.

Анализ образовательной программы специальности «Строительство и гражданская инженерия» показывает, что наибольшее количество учебных часов выделено на следующие предметы: на «Инженерную и компьютерную графику» и «Инженерную геодезию» - по 6 кредитов на первом курсе (1 кредит - 30 часов), в третьем семестре 4,5 кредита на «Сопротивление материалов» и 5 кредитов на «Строительное материаловедение и металловедение», а в четвертом семестре - 6 кредитов на «Механику строительных конструкций, жидкостей и газов» и 4 кредита на «Архитектуру зданий и сооружений». И если терминология «Компьютерной графики» частично усваивается иностранными студентами на еще подфаке, где должен читаться курс информатики, то изучение геодезии, к сожалению, не предваряется никакой языковой работой. Поэтому улучшить языковую подготовку будущих строителей можно созданием соответствующих учебных материалов - в дополнение к существующим или для их корректировки. Тематика занятий по языку обучения для студентов вторых курсов строительных специальностей, как показал анализ используемых в ХНУСА учебных пособий, коррелирует с изучаемыми предметами, и необходимо лишь дополнить имеющиеся материалы двумя-тремя уроками, посвященными свойствам материалов.

\section{ЗАКЛЮЧЕНИЕ}

Предлагаемые изменения и дополнения должны сначала получить лингвистическое и методическое обоснование, а затем пройти обсуждение как внутри авторских коллективов, так и на уровне кафедрального семинара и со всеми заинтересованными. Вероятно, окажется наиболее рациональным апробировать подобные нововведения уже на новых учебных материалах, запланированных сотрудниками кафедры в связи с переходом подготовки иностранных студентов в Украине на государственный язык.

\section{REFERECES}

Belikova Ye.V. (2017). Praktikum k izucheniyu distsipliny «Russkiy yazyk kak inostrannyy» «Chitayem teksty po spetsial'nosti» [Practicum for the study of the discipline "Russian as a foreign language" "We read texts in the specialty"] / Ye.V. Belikova, N.N. Bessonova, O.A. Greul, T.V. Krech. - Khar'kov : KHNUSA, p. 112 . 
Belikova Ye.V. (2019). Chitayem teksty samostoyatel'no: praktikum po russkomu yazyku kak inostrannomu: navchal'niy posíbnik [We read the texts ourselves: a workshop on Russian as a foreign language: a master book] / Ye.V. Belikova, N.N. Bessonova, O.A. Greul. - Khar'kov : KHNUSA, p.114

Belikova Ye.V. (2020). Shag v professiyu. Praktikum po razvitiyu rechi dlya inostrannykh soiskateley vysshego obrazovaniya spetsial'nosti 191 «Arkhitektura i gradostroitel'stvo» [Step into the profession. Workshop on the development of speech for foreign applicants for higher education in specialty 191 "Architecture and urban planning"] / Ye.V. Belikova, N.N. Bessonova, O.A. Greul. - Kharkív : Vidavnitstvo Ívchenka, p. 186.

Bessonova N.N. (2017). Praktikum k izucheniyu distsipliny «Russkiy yazyk kak inostrannyy» «Uchimsya chitat' teksty po spetsial'nosti» [Practicum for the study of the discipline "Russian as a foreign language" "Learning to read texts in the specialty"]/ N.N. Bessonova, V.V. Ignatova, M.A. Khodakovskaya. Khar'kov : KHNUSA, p. 120.

Krech, T. \& Milieva, I. (2019) Linguo-methodological aspect of overcoming interference in teaching foreign students a second non-native language $\backslash$ International Scientific-Pedagogical Organization of Philologists “WEST-EAST" (ISPOP). Scientific Journal "WEST-EAST”. Vol. 2\1, N2 (October, 2019). pp. 105-109 doi: https://doi.org/10.33739/2587-5434-2019-2-2-105-109

Skrypnik L.V., Chernogorskaya N.G. (2020). Shag v professiyu. Praktikum po razvitiyu rechi dlya inostrannykh soiskateley vysshego obrazovaniya po spetsial'nosti 192 «Stroitel'stvo i grazhdanskaya inzheneriya». [Step into the profession.] - Khar'kov : KHNUSA, p. 120.

Petrushova O.V. (2006). Nauchnyy stil' dlya studentov-inostrantsev 1 kursa tekhnicheskikh spetsial'nostey [Scientific style for 1st year foreign students of technical specialties] / O.V. Petrushova, I.I. Chernenko, G.A. Slavtich. - Khar'kov. - Kompaniya «Smit». p. 316.

Petrushova O.V. (2007). Sbornik uprazhneniy po grammatike russkogo yazyka dlya studentov inostrantsev osnovnogo etapa obucheniya [Collection of exercises on the grammar of the Russian language for foreign students of the main stage of education] / O.V. Petrushova, I.I. Chernenko, O.N. Trostinskaya, A.V. Tarleva. - Khar'kov. - Kompaniya «Smit». p. 290.

Yasnitskaya I.A. (1994). Nauchnaya rech' dlya nachinayushchikh: Biologiya, khimiya, fizika : posobiye [Scientific speech for beginners: Biology, chemistry, physics] / I.A. Yasnitskaya, L.A. Orlova, T.A.Snegurova i dr. - Khar'kov : Osnova, p. 142.

\section{For citation:}

Elena Mospan \& Natalia Bessonova \& Olga Greul (2020). Teaching the scientific style of the rivers of the future architects and builders in KNUCA: achievements, problems, perspectives // International Scientific-Pedagogical Organization of Philologists "WEST-EAST" (ISPOP). Scientific Journal "WESTEAST”. Vol. 3, N1 (October, 2020). pp. 70-77. https://doi.org/10.33739/2587-5434-2020-3-70-77

\section{Для цитирования:}

Мосьпан, Е., Бессонова, Н., Греул, О. (2020)

Обучение научному стилю речи будущих архитекторов и строителей в ХНУСА: достижения, проблемы, перспективы // International Scientific-Pedagogical Organization of Philologists "WESTEAST" (ISPOP). Scientific Journal "WEST-EAST". Vol.3, N1 (October, 2020). c. 70-77. https://doi.org/10.33739/2587-5434-2020-3-70-77 
Information about the authors:

Elena Mospan - PhD, Associate Professor of the Department of Ukrainian Language and Language Training of Foreign Citizens, Kharkiv National University of Construction and Architecture, Kharkiv, Ukraine.

e-mail: elena.mospan@gmail.com

Natalia Bessonova - Senior lecturer of the Department of Ukrainian Language and Language Training of Foreign Citizens, Kharkiv National University of Construction and Architecture, Kharkiv, Ukraine.

e-mail: bessonova.natalya.ua@gmail.com

Olga Greul - Senior lecturer of the Department of Ukrainian Language and Language Training of Foreign Citizens, Kharkiv National University of Construction and Architecture, Kharkiv, Ukraine.

e-mail: gruel.olga@gmail.com

\title{
Сведения об авторах:
}

Мосьпан Елена Паловна- кандидат филологических наук, доцент кафедры украинского языка и языковой подготовки иностранных граждан, Харьковский национальный университет строительства и архитектуры, Харьков, Украина.

e-mail: elena.mospan@gmail.com

Бессонова Наталия Николаевна - старший преподаватель кафедры украинского языка и языковой подготовки иностранных граждан, Харьковский национальный университет строительства и архитектуры, Харьков, Украина.

e-mail: bessonova.natalya.ua@gmail.com

Греул Ольга Александровна - старший преподаватель кафедры украинского языка и языковой подготовки иностранных граждан, Харьковский национальный университет строительства и архитектуры, Харьков, Украина.

e-mail: gruel.olga@gmail.com

Manuscript received: 13/08/2020

Accepted for publication: $14 / 09 / 2020$

Рукопись получена: 13/08/2020

Принята к печати: 14/09/2020

\author{
International Scientific-Pedagogical Organization of Philologists "West-East" - ISPOP \\ SCIENTIFIC JOURNAL "WEST-EAST" \\ ISSN (print) - 2587-5434 ISSN (online) - 2587-5523
}

